\title{
Síndrome da fibrose sub-retiniana difusa: Relato de três casos
}

\section{Diffuse subretinal fibrosis syndrome:description of threecases}

\author{
Pedro Durães Serracarbassa ${ }^{1}$ \\ Cinara Lagos ${ }^{2}$ \\ Suel Abujamra ${ }^{3}$
}

${ }^{1}$ Doutor em Oftalmologia e Médico colaborador do Departamento de Oftalmologia da Faculdade de Medicina da Universidade de São Paulo.

${ }^{2}$ Estagiária do Departamento de Oftalmologia do Hospital A. C. Camargo.

${ }^{3}$ Professor Associado do Departamento de Oftalmologia da Faculdade de Medicina da Universidade de São Paulo e Professor Titular da Disciplina de Oftalmologia da Universidade de Santo Amaro.

Endereço para correspondência: Av. Brig. Faria Lima 1903, cj. 43 - São Paulo (SP) CEP 01452-001.

E-mail: serracar@wac.com.br

Recebido para publicação em 05.03.2001 Aceito para publicação em 20.12.2001

\section{RESUMO}

Os autores descrevem três casos de uma entidade rara, a síndrome da fibrose sub-retiniana difusa. Relatam as características clínicas da doença, os achados fundoscópicos e os resultados após a terapia com corticosteróides. Analisam ainda os diagnósticos diferenciais entre as doenças que compõem a síndrome dos pontos brancos por meio de revisão da literatura. Como conclusão, ressaltam a importância do diagnóstico e tratamento precoce da síndrome da fibrose sub-retiniana difusa no intuito de prevenir o acometimento do olho contralateral.

Descritores: Fibrose/diagnóstico; Fibrose/terapia; Doenças da coróide; Doenças retinianas Coroidite/patologia; Retina/patologia; Síndrome; Adulto

\section{INTRODUÇÃO}

A Síndrome da fibrose sub-retiniana difusa foi descrita inicialmente em 1984 por Palestine ${ }^{(1-2)}$. A partir desta descrição, muitas outras foram relata$\operatorname{das}^{(3-5)}$ associando a doença à Síndrome dos pontos brancos. Outras três entidades fariam parte: a síndrome dos pontos brancos evanescentes (MEWDS), a coroidopatia puntata interna (PIC) e a coroidite multifocal com panuveíte. A fibrose sub-retiniana é uma doença rara que atinge principalmente mulheres de raça negra, jovens, entre a adolescência e terceira década. Apresenta evolução rápida e progressiva, com acometimento inicialmente unilateral, atingindo o olho contralateral em um período de seis meses. É caracterizada por lesões amareladas, profundas, acometendo o epitélio pigmentado da retina (E.P.R.) e coróide, localizadas no pólo posterior, que coalescem em semanas evoluindo para extensas áreas de cicatrizes sub-retinianas. A histopatologia revela espesso tecido fibroso subretiniano e infiltrado granulomatoso linfocitário na coróide ${ }^{(6)}$. O prognóstico visual destes pacientes é reservado e a resposta ao tratamento com altas doses de corticosteróides é limitada. O objetivo deste estudo é apresentar uma descrição de três casos presumidos da síndrome da fibrose subretiniana difusa e discutir os aspectos do diagnóstico diferencial e tratamento da doença.

\section{RELATOS DOS CASOS}

\section{Caso 1}

M. A. A. M., 50 anos, sexo feminino, branca, natural de São Paulo - SP. Apresentava-se com queixa de diminuição progressiva da acuidade visual 
em ambos os olhos (AO) há três meses, com melhora espontânea da visão no olho esquerdo (OE) e piora da acuidade visual no olho direito (OD) há 15 dias. Não foram relatados outros sintomas oculares. Os antecedentes oculares pessoais e familiares encontravam-se dentro da normalidade. Apresentava acuidade visual com correção de conta dedos a 1 metro no OD e 20/30 no OE. Os demais dados do exame ocular eram normais, exceto a fundoscopia, onde se constatou no olho direito: Turvação vítrea leve, proliferação fibrosa sub-retiniana atingindo grande porção do pólo posterior e lesões amareladas sub-retinianas bem delimitadas próximas às arcadas vasculares (Figura 1). No olho esquerdo observou-se proliferação fibrosa sub-retiniana peri-papilar sem sinais de atividade inflamatória. A paciente foi submetida à investigação diagnóstica laboratorial para toxoplasmose, sarcoidose, sífilis, tuberculose, histoplasmose e mononucleose, nos quais não foram encontradas alterações. Foi tratada com $100 \mathrm{mg}$ de prednisolona via oral durante 60 dias, evoluindo com quadro cicatricial das lesões ativas no OD e acuidade visual de conta dedos a 1 metro no OD e 20/30 no OE.

\section{Caso 2}

P.C.L., 35 anos, sexo masculino, pardo, natural e procedente de São Paulo - SP. Apresentava queixa de perda progressiva da acuidade visual há dois meses em AO sem outros sintomas oculares. Os antecedentes oculares, pessoais e familiares encontravam-se dentro da normalidade. Apresentava acuidade visual de movimento de mãos em AO. O restante do exame ocular apresenta-se normal, exceto a fundoscopia, onde se observavam em AO: extensas áreas de proliferação fibrosa sub-retiniana no pólo posterior acometendo região macular (Figura 2). Foi submetido à investigação diagnóstica para toxoplasmose, sarcoidose, histoplasmose, sífilis e mononucleose, estando estes sem alterações. O paciente não foi tratado devido ao aspecto cicatricial das lesões.

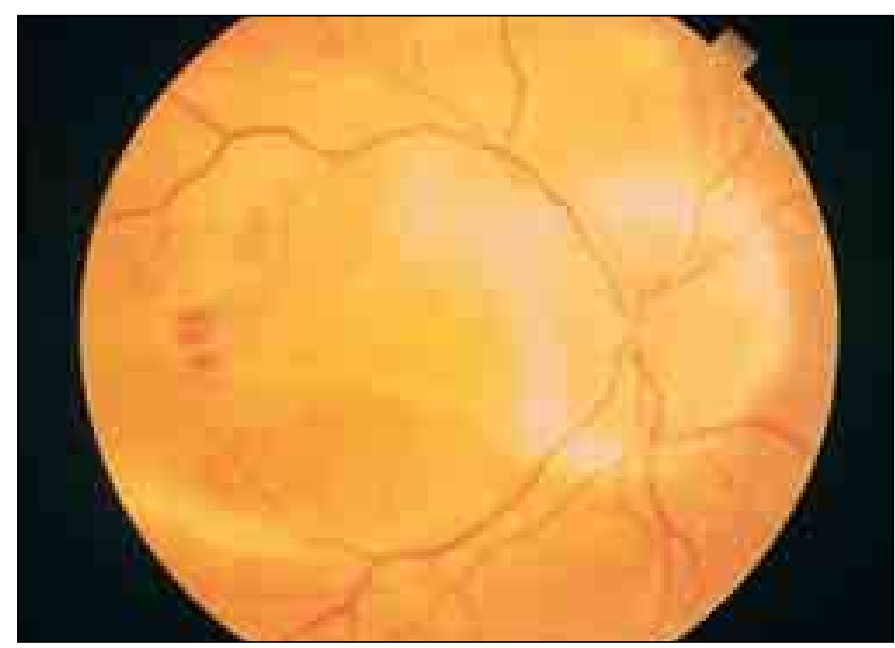

Figura 1 - Lesões amareladas, sub-retinianas, coalescentes, em atividade

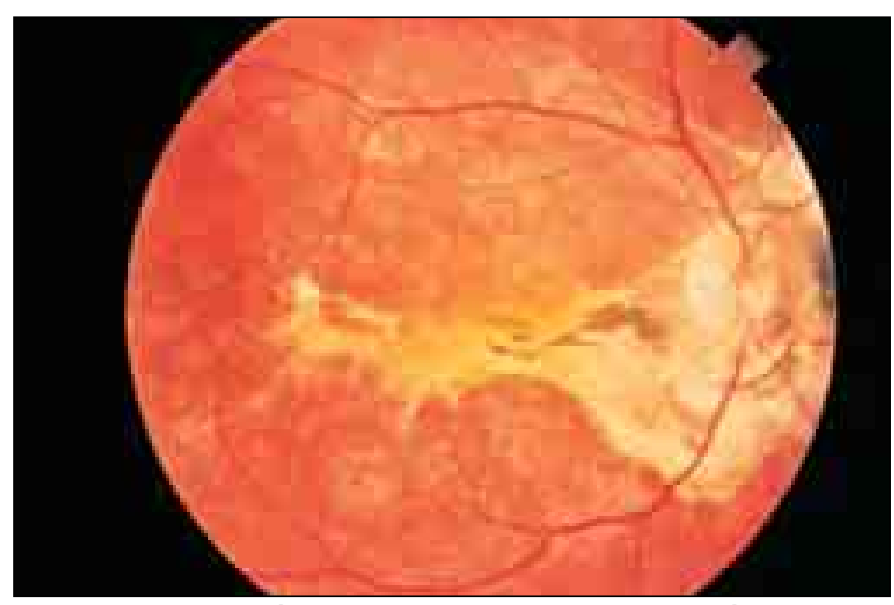

Figura 2 - Extensas áreas de fibrose sub-retiniana no pólo posterior

\section{Caso 3}

G. B. S. S., 20 anos, sexo feminino, parda, natural e procedente de São Paulo - SP. Apresentava queixa de perda da acuidade visual no OD há 1 mês. Relata diminuição da visão em AO há 4 anos por inflamação (SIC) com piora de visão no OE e melhora no OD. Nos antecedentes pessoais relatava sarcoidose (SIC). Os antecedentes familiares encontravam-se normais. A acuidade visual era 20/200 no olho OD e percepção luminosa no OE. Na biomicroscopia observam-se precipitados ceráticos finos e inferiores no OD e catarata sub-capsular posterior e seclusão pupilar no OE. Os demais exames oculares encontravam-se normais exceto a fundoscopia, onde se observavam no OD: múltiplas lesões amareladas, profundas, no pólo posterior, intercaladas por proliferação fibrosa subretiniana. Apresentava ainda inflamação vítrea leve (Figura 3). No olho esquerdo observou-se: extensa área de proliferação fibrosa sub-retiniana no pólo posterior. Foi submetida à investigação diagnóstica onde se constatou aumento da enzima

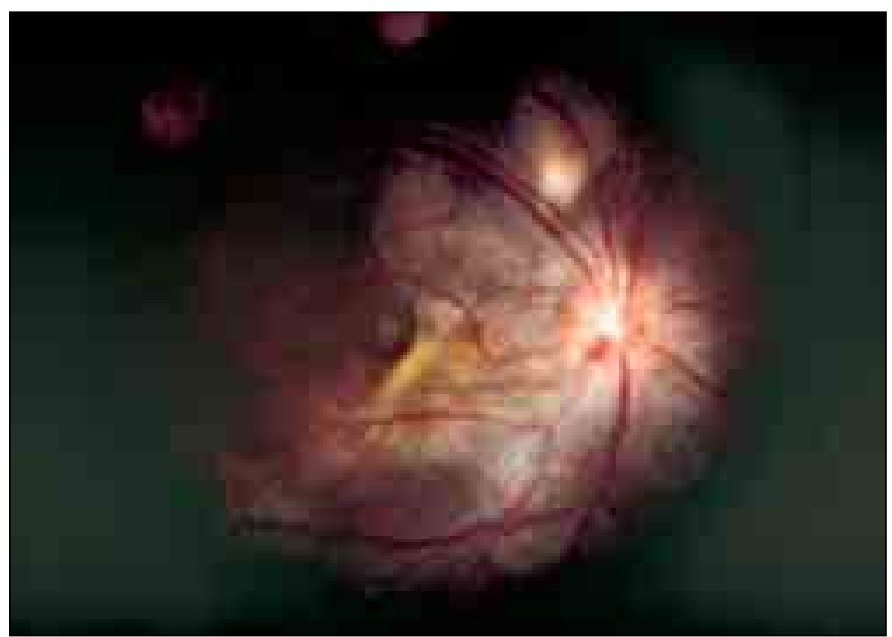

Figura 3 - Múltiplas lesões amareladas, profundas, isoladas, acometendo o pólo posterior 
conversora da angiotensina e aumento da região hilar na radiografia do tórax, dados estes sugestivos de sarcoidose. $\mathrm{O}$ estudo histopatológico do tecido retirado através de biópsia conjuntival e o mapeamento corporal com Gáleo, não apresentaram indícios de sarcoidose. Foi tratada com $100 \mathrm{mg}$ de prednisolona via oral com melhora da vitreíte e cicatrização das lesões ativas no OD.

\section{DISCUSS ÃO}

A etiologia da síndrome dos pontos brancos é motivo de controvérsia na literatura. Alguns autores ${ }^{(4,7)}$ acreditam que a síndrome corresponda a diferentes formas clínicas de uma mesma doença. Outros porém ${ }^{(5)}$, afirmam que as quatro doenças seriam entidades distintas. Cerca de metade dos pacientes portadores da síndrome têm história pregressa de doença viral, principalmente os pacientes portadores de $\operatorname{MEWDS}^{(8)}$. Em nenhum dos nossos casos descritos, encontramos história pregressa de doença viral. Associações com quadros sistêmicos são descritos na literatura, como a sarcoidose ${ }^{(9)}$, mononucleose $^{(7)}$ e a histoplasmose ${ }^{(9)}$. Em nossos relatos, encontramos uma possível associação com sarcoidose em um caso. Porém, trata-se de um diagnóstico presumido, uma vez que ocorreu a confirmação no exame histopatológico. Notamos ainda que, o quadro clínico demonstrado em nosso relato, não corresponde às descrições de coroidite por sarcoidose da literatura. Estas descrevem a presença de pequenas lesões amareladas, profundas, na retina periférica inferior, dado este não encontrado no nosso caso. A síndrome da fibrose sub-retiniana difusa apresenta diferenças e similaridades em relação às outras três entidades. Os pacientes são, na sua grande maioria, jovens da raça negra, sexo feminino, com maior variabilidade da faixa etária, naqueles portadores de coroidite multifocal. Em nossos relatos, um paciente era do sexo masculino e dois do sexo feminino. Dois pacientes eram adultos jovens $(20$ e 35 anos) e um apresentava 50 anos de idade. Dois pacientes eram da raça negra e um era pertencente à raça branca. Os sintomas apresentaram-se similares, com diminuição da acuidade visual, fotopsias e escotomas.

$\mathrm{O}$ quadro clínico da fibrose sub-retiniana difusa assemelha-se ao da PIC e coroidite multifocal. As lesões são amareladas, acometem o epitélio pigmentar da retina e coróide, medem em torno de $300 \mu \mathrm{m}$ e situam-se principalmente no pólo posterior. As lesões da MEWDS diferem das restantes por serem menores e mais superficiais. A inflamação do corpo vítreo é encontrada nos portadores de coroidite multifocal e fibrose sub-retiniana. O diagnóstico diferencial se faz principalmente pelo curso clínico das lesões. $\mathrm{Na}$ fibrose sub-retiniana, as lesões coalescem, formando extensas áreas de fibrose abaixo da retina em poucas semanas. A coroidite multifocal e PIC costumam evoluir com cicatrizes de coróide e epitélio pigmentado da retina, diferentemente da MEWDS, onde as lesões desaparecem sem deixar alterações do EPR. São outros diag- nósticos diferenciais: sífilis, tuberculose, epiteliopatia pigmentar placóide multifocal posterior aguda, retinocoroidopatia de Birdshot, coroidopatia serpiginosa e toxoplasmose. Nossos relatos correspondem às descrições clínicas da literatura, com baixa da acuidade visual rápida e progressiva em ambos os olhos, presença de lesões profundas e amareladas no pólo posterior com extensas áreas de fibrose sub-retiniana. O prognóstico visual dos pacientes portadores de fibrose sub-retiniana é reservado, sendo que a maioria geralmente evolui com acuidade visual igual ou menor que 20/400 em poucos meses, devido à formação de cicatrizes fibrosas maculares ou edema macular cistóide. As recidivas são freqüentes na fibrose sub-retiniana e coroidite multifocal, sendo menos comuns na PIC e raras na MEWDS. A coroidite multifocal apresenta um prognóstico variável, dependendo ou não da presença de membrana neovascular coroidal subfoveal, edema macular cistóide e cicatrizes maculares ${ }^{(7)}$. Os casos de MEWDS e PIC apresentam bom prognóstico visual, exceto aqueles que desenvolvem membrana neovascular coroidal na fóvea ${ }^{(8)}$. Nos casos relatados neste trabalho, apenas um olho de um paciente apresentou acuidade visual de 20/30 e os restantes obtiveram acuidade visual de 20/200 a movimento de mãos. O tratamento da fibrose sub-retiniana difusa consiste no uso de altas doses de corticosteróides via oral e imunossupressores em alguns casos de evolução desfavorável. Em geral, estes pacientes apresentam pouca resposta a esta terapia, evoluindo freqüentemente com grandes áreas de fibrose sub-retiniana. Opta-se pelo tratamento no intuito de preservar o olho adelfo ${ }^{(9)}$. Os pacientes do presente estudo, submetidos a altas doses de corticoterapia por longos períodos, evoluíram com proliferação fibrosa sub-retiniana no local das lesões ativas. Como relatado acima, somente um dos olhos relatados apresentou acuidade visual de 20/30 durante o período do tratamento, porém o tempo de seguimento destes pacientes foi de apenas 60 dias.

Concluímos portanto que, a síndrome da fibrose sub-retiniana difusa é uma entidade que apresenta características distintas das demais formas clínicas da síndrome dos pontos brancos e que sua diferenciação é de extrema importância no intuito de preservar o olho contralateral com altas doses de corticoterapia ou imunossupressão.

\section{ABSTRACT}

The authors describe three cases of a rare disease, the diffuse subretinal fibrosis syndrome. They report clinical aspects, fundoscopic features and outcomes after steroid therapy. They also analyze the differential diagnosis between the diseases of white dot syndrome by reviewing the literature. In conclusion, they point out the meaning of early diagnosis and treatment of diffuse subretinal fibrosis syndrome in order to prevent the progression to the fellow eye. 
Keywords: Fibrosis/diagnosis; Fibrosis/therapy; Choroid diseases; Retinal diseases; Choroiditis/pathology; Retina/pathology; Syndrome; Adult

\section{REFERÊNCIAS}

1. Palestine AG, Nussenblatt RB, Parver LM, Knox DL. Progressive subretinal fibrosis and uveitis. Br J Ophthalmol 1984;68:667-73.

2. Palestine AG, Nussenblatt RB, Chan CC, Hooks JJ, Firedman L, Kuwabara T. Histopathology of the subretinal fibrosis and uveitis syndrome. Ophthalmology 1985;92:838-44.

3. Cantrill HL, Folk JC. Multifocal choroiditis associated with progressive subretinal fibrosis. Am J Ophthalmol 1986;101:170-80.
4. Morgan CM, Schtaz H. Recurrent multifocal choroiditis. Ophthalmology 1986; 93:1138-47.

5. Charteris DG, Lee WR. Multifocal posterior uveitis: clinical and pathological findings. Br J Ophthalmol 1990;74:688-93.

6. Kim MK, Chan CC, Belfort Jr R, Farah M, Burnier MP, Nussenblatt RB et al. Histopathologic and Immunohistopathologic features of subretinal fibrosis and uveitis syndrome. Am J Opthalmol 1987;104:15-23.

7. Folk JC, Pulido JS, Wolf MD. Focal points: white dot chorioretinal inflammatory syndromes. 1990 Clinical Modules for Ophthalmologists. American Academy of Ophthalmology 1990;8 [Module 11].

8. Jampol LM, Sieving PA, Pugh D, Fishman GA, Gilbert H. Multiple evanescent white dot syndrome. I - clinical findings. Arch Ophthalmol 1984; 102:671-4.

9. Folk JC. White dot chorioretinal inflammatory syndromes. In: Lewis H, Ryan SJ, editors. Medical and Surgical Retina. St Louis: Mosby; 1994. p.385-91.

\title{
$6^{0}$ \\ CONGRESSO \\ $\mathrm{DE}$

OFTALMOLOGIA

\section{7 a 09 de Novembro de 2002}

\author{
Pavilhão de Eventos da Faculdade de Medicina do \\ Triângulo Mineiro - Uberaba - MG
}

\section{Promoção: Sociedade de Oftalmologia do Triângulo Mineiro}

INFORMAC̣ÕES: Telf.: (34) 3338-5343 • Fax: (34) 3312-0657

E-mail:diretoria.pa@terra.com.br 